\title{
A New Method for Designing Dense Skeleton Asphalt Mixture Based on Meso Parameter
}

\author{
Liwan Shi $\mathbb{D}^{1,2}$ Duanyi Wang $\mathbb{D}{ }^{2}{ }^{2}$ Junfeng Wang, ${ }^{3}$ Zhonghai Jiang, ${ }^{1}$ Hehao Liang, ${ }^{2}$ \\ and Xiao Qin ${ }^{1,4}$ \\ ${ }^{1}$ Advanced and Sustainable Infrastructure Materials Group, School of Transportation and Civil Engineering and Architecture, \\ Foshan University, Foshan 528225, China \\ ${ }^{2}$ School of Civil Engineering and Transportation, South China University of Technology, Guangzhou 510640, China \\ ${ }^{3}$ College of Civil Engineering and Architecture, Hainan University, Haikou 570228, China \\ ${ }^{4}$ School of Highway, Chang'an University, Xi'an 710064, China \\ Correspondence should be addressed to Duanyi Wang; tcdywang@scut.edu.cn
}

Received 6 May 2019; Accepted 27 September 2019; Published 17 February 2020

Academic Editor: Hao Wang

Copyright (c) 2020 Liwan Shi et al. This is an open access article distributed under the Creative Commons Attribution License, which permits unrestricted use, distribution, and reproduction in any medium, provided the original work is properly cited.

\begin{abstract}
At present, research on the internal structures of asphalt mixtures has mostly focused on the statistical analysis of their mesostructural components such as aggregates, voids, and asphalt mortars, in addition to the verification of the mechanical behaviour of the mixture through simulations. Furthermore, the capacity of the research has not risen to a level where a design method to guide the design and optimisation of the asphalt mixture gradation has been formulated. After an in-depth analysis of the existing evaluation parameters and standards for the asphalt mixture skeleton, this study proposes a new method for precise designing a dense skeleton asphalt mixture (DSAM) based on meso parameter. The results indicate that the application of digital image processing (DIP) techniques to adjust the gradation increases the average coordination number $\left(\bar{n}_{\mathrm{c}}\right)$ and reduces the ratio of the quantity of coarse aggregate without contact point to the total quantity of coarse aggregate ( $C$ value). This can effectively improve the meso parameters of the mixture so that the quality of the main skeleton is significantly enhanced; the process also has higher precision and demands less test work. VCA mix $_{\text {(IMAGE }) \leq}$ $\mathrm{VCA}_{\mathrm{DRC}}$ and $\bar{n}_{\mathrm{c}}>1.6$ while $C<20 \%$ can be used as qualitative and quantitative evaluation criterion for forming better main skeleton structure of coarse aggregate. The new method of designing a DSAM based on meso parameter is intuitive and convenient, which considerably reduces the blindness and tediousness in the design of the asphalt mixture gradation. The engineering example also proves that the asphalt mixture has an excellent pavement performance and verifies the feasibility of the proposed design method.
\end{abstract}

\section{Introduction}

The dense skeleton asphalt mixture (DSAM) is a type of heavy-duty traffic pavement material. The typical characteristics of the material structure are as follows: the coarse aggregate in the asphalt mixture constitutes the main skeleton; the fine aggregate, asphalt, and other admixtures constitute the asphalt mortar that fills the voids of the skeleton formed by the coarse aggregates and binds and restrains it so that the asphalt mixture forms a whole material with high strength. With the rapid increase in heavy-duty vehicles, the DSAM has been widely used in China's highway construction because of its good antirutting performance. Currently, the research and application of skeleton structures is mainly based on the description of the dense skeleton structure in the "SMA mixing proportion design method" proposed by the Federal Highway Administration (FHWA) and the National Asphalt Pavement Association (NAPA), USA. An inequality qualitative empirical formula, $\mathrm{VCA}_{\text {mix }}<\mathrm{VCA}_{\mathrm{DRC}}$, is used as the evaluation parameter of the coarse aggregate skeleton [1]. In this inequality, $\mathrm{VCA}_{\text {mix }}$ is the percent of voids in the coarse mineral aggregate in the asphalt mixture and $\mathrm{VCA}_{\mathrm{DRC}}$ is the percent of voids in the coarse mineral aggregate in the dryrodded condition. However, in the process of $\mathrm{VCA}_{\text {mix }}$ and $\mathrm{VCA}_{\mathrm{DRC}}$ calculation, irrespective of whether $\mathrm{VCA}_{\text {mix }}$ or $\mathrm{VCA}_{\mathrm{DRC}}$ is based on the macroparameter calculated from the test, there are considerable differences not only in the methods of preparing specimens but also in the methods of 
calculating their volume parameters. After introducing the empirical parameter (e.g., $C$ value when estimating the influence of adsorbed asphalt on aggregate density), it is likely that the calculation results will have errors owing to factors such as the value of empirical coefficient and accumulation of artificial errors. Many researchers [2,3] have recognised that the existing skeleton evaluation criteria cannot guide the design of DSAMs and have introduced indicators such as skeleton density, skeleton distraction, and grading interference coefficient. Nevertheless, the above parameters are basically revised on the basis of $\mathrm{VCA}_{\text {mix }}$, the evaluation parameter is often obtained through calculations on the basis of experience, and the accumulated error may still large.

In order to have a better understanding of the internal structure of asphalt mixtures, many researchers have turned their attention to the study of the microstructural characteristics of the materials, hoping to improve their macromechanical properties through an in-depth understanding of the asphalt mixture microstructure. At present, there are two main methods to identify and analyse the internal microstructure of the asphalt mixture, namely, the digital image processing (DIP) techniques $[4,5]$ and numerical analysis methods (NAMs) [6-8]. The spatial distribution of aggregates, voids, and asphalt mortar in the asphalt mixture and its mesomechanical behaviour can be studied by the DIP. Bessa et al. [9] aimed at characterising the internal structure of various hot mix asphalts (HMAs) by using different software types, and the results showed that DIP characterisation is easier, faster, and can provide more complete and accurate results than those obtained from lab tests. Laboratory tests present average values while image analyses present the statistical distribution of every parameter. Several studies have been conducted characterising the HMA internal structure through DIP techniques, and different scholars have employed different methods to analyse the internal structure characteristics of various pavement materials, gradation types, and compaction methods [10]. Parameters to measure the aggregate size, coarse aggregate angularity [11], contact between aggregates [12], skeleton performance [13, 14], thermal conductivity $[15,16]$, mastic thickness [17], air void distribution [18], and horizontal homogeneity $[19,20]$ of asphalt mixtures prepared from the laboratory or field have been proposed. These studies have found that most of these parameters could be significantly influenced by the mix design results or test conditions during the compaction process. Moreover, it has been verified that there is a strong relationship between the internal structure and macroperformance of the asphalt mixture [21]. Meanwhile, research findings show that there is a strong correlation between the internal skeleton structure parameters of contact points, aggregate size, and inclination angle and the rutting performance of the HMA [20, 22].

Although there are many research papers on the internal structure of asphalt mixtures at present, they are still in the stage of statistical analysis of the mesostructural characteristics and verification of the mechanical behaviour of the asphalt mixture through simulations. The capacity of the research has not risen to a level where a design method to guide the design and optimisation of the asphalt mixture gradation has been formulated $[23,24]$. Based on the above background, combined with the author's in-depth analysis of the meso evaluation parameters and standards for the asphalt mixture skeleton, a new design process and method for precise designing DSAMs based on meso parameter is proposed to realize precise design of mesostructure of asphalt mixture in this study.

\section{Skeleton State of Asphalt Mixture and Multilevel Mixing Method}

In order to meet the needs of heavy-duty traffic and take into account the economy, the design of DSAM has been paid more and more attention in recent years. To design an ideal main skeleton structure, on the one hand, coarse aggregates are interlocked each other to form a main skeleton; on the other hand, the main skeleton should not be interfered by excessive fine aggregate. Figure 1(a) is a dense main skeleton formed by contact of coarse aggregates. Figure 1(b) is a loose main skeleton formed by coarse aggregates due to a little more fine aggregate. If fine aggregate content continues to increase, the main skeleton will be propped up and interfered by excessive fine aggregate, which deviates from the original design goal of the dense skeleton structure, as shown in Figure 1(c). Therefore, the amount of fine aggregate should be appropriate, too small amount of fine aggregate cannot fully fill the voids between main skeleton, resulting in excessive voids of asphalt mixtures, and too large amount of fine aggregate will interfere with main skeleton. The goal of gradation design of DSAM is that coarse aggregate constitutes the main skeleton; the fine aggregate, asphalt, and other admixtures constitute the asphalt mortar that fills the voids of the skeleton formed by the coarse aggregates and does not interfere with the main skeleton and finally forms a whole material with high strength. This is one of the difficulties in the current design process.

As one of the skeleton structure design methods, aggregate multilevel mixing was first proposed by Kapolyi and Lees [25] in the 1970s based on the theory of the maximum compactness of aggregates. Then, Kapolyi established a mathematical model to describe the properties of aggregates with different proportions. Lees extended the densest concept of the two-particle-size system to the multi-particle-size system by considering two-particle-size elements each time. When the mixture of the two-particle-size elements reaches the minimum void, the corresponding proportion of coarse and fine aggregates can be determined, and then the mixture, as a new particle-size element, is mixed with the next grade of particle-size elements, until the most compact mixture is prepared [26]. The operation steps are as follows: the maximum size aggregate is taken as the coarse aggregate and the smaller size aggregate as the fine aggregate, which are then mixed in different proportions. When the mixture reaches the minimum percentage of voids in the aggregates, the corresponding proportion of coarse and fine aggregates is considered to be the optimal proportion to form the skeleton. Then, the mixture of this proportion which reaches the minimum percentage of voids is taken as coarse 


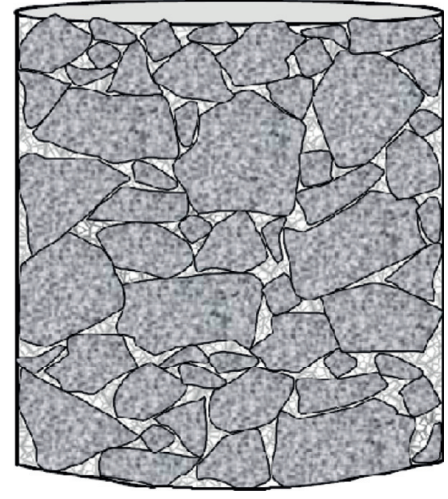

(a)

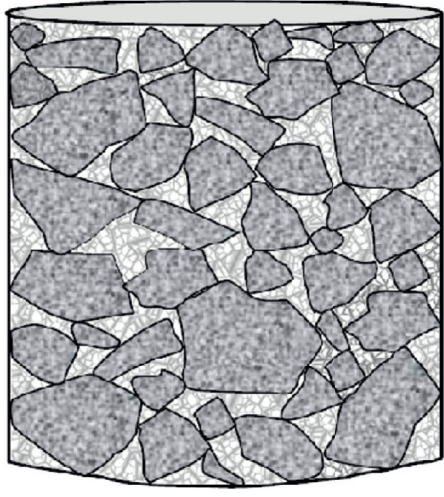

(b)

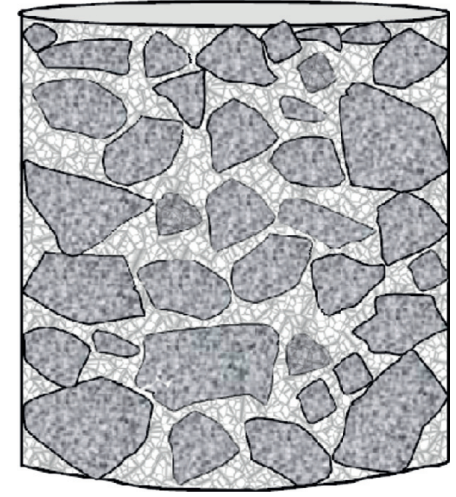

(c)

Figure 1: Skeleton state: (a) dense skeleton; (b) loose skeleton; (c) fine aggregate interference.

aggregate, mixed with the next grade of particle-size aggregate, until the optimal skeleton structure is obtained.

As shown in Figure 2, the order of the four aggregates by particle size is $\mathrm{A}>\mathrm{B}>\mathrm{C}>\mathrm{D}$, and the proportion of the four aggregates corresponding to the densest state is assumed to be a, b, c, and d, respectively. The operational procedure for mixing the four-particle-size aggregates into the optimal skeleton mixture is as follows:

(i) First step: mixing aggregates $\mathrm{A}$ and $\mathrm{B}$ with proportions $\mathrm{a}$ and $\mathrm{b}$

(ii) Second step: the mixture $A B$ is regarded as an aggregate, mixing $\mathrm{AB}$ and $\mathrm{C}$ with proportions $\mathrm{a}+\mathrm{b}$ and $c$

(iii) Third step: the mixture $A B C$ is regarded as an aggregate, mixing $\mathrm{ABC}$ and $\mathrm{D}$ with proportions $\mathrm{a}+\mathrm{b}+\mathrm{c}$ and $\mathrm{d}$

However, the main problem in this operational process is that when mixing the fine aggregate, because the particle size is too small, the mixture segregation is serious, and the experimental results have great variability. For this reason, many researchers $[27,28]$ have optimised and improved the design method, for example, by dividing the mixing process into two parts and mixing the coarse and fine aggregates separately, using three parameters, $R_{\mathrm{cA}}, R_{\mathrm{FAc}}$, and $R_{\mathrm{FAf}}$, to adjust the gradation curve in detail, and limiting the amount of asphalt by controlling the ratio of powder to binder. All of the measures will eventually be readjusted for the designed gradation. Although some of the problems in the grade mixing process have been solved to a certain extent, it is still unknown whether the final grading curve after adjustment interferes or not and whether the coarse aggregate is fully interlocked to get a better skeleton structure, and there is no clear evaluation criterion. Therefore, this is the key problem to be solved in this study.

\section{Evaluation Parameter of Skeleton Structure}

3.1. Existing Evaluation Parameter and Problems. At present, the asphalt mixture skeleton structure (Figure 1) is only evaluated by an inequality qualitative standard,
$\mathrm{VCA}_{\text {mix }} \leq \mathrm{VCA}_{\mathrm{DRC}}$. When $\mathrm{VCA}_{\text {mix }}<\mathrm{VCA}_{\mathrm{DRC}}$, the coarse aggregates are interlocked to form the skeleton; when $\mathrm{VCA}_{\text {mix }} \equiv \mathrm{VCA}_{\mathrm{DRC}}$, the coarse aggregates just form a noninterference effect; if $\mathrm{VCA}_{\text {mix }}>\mathrm{VCA}_{\mathrm{DRC}}$, the coarse aggregate skeleton is propped up, and the fine aggregate and asphalt mortar interfere with the coarse aggregate skeleton. $\mathrm{VCA}_{\text {mix }}$ is generally calculated according to the following equation:

$$
\mathrm{VCA}_{\text {mix }}=\left(1-\frac{\gamma_{\mathrm{f}}}{\gamma_{\mathrm{ca}}} \times P_{\mathrm{ca}}\right) \times 100,
$$

where $\mathrm{VCA}_{\text {mix }}$ is the percent of voids in the coarse mineral aggregate in the asphalt mixture; $\mathrm{VCA}_{\mathrm{DRC}}$ is the percent of voids in the coarse mineral aggregate in the dry-rodded condition; $\gamma_{\mathrm{f}}$ is the bulk specific gravity of the asphalt mixture by the surface dry method; $\gamma_{\mathrm{ca}}$ is the bulk density of all the coarse aggregates in the mineral aggregate; and $P_{\mathrm{ca}}$ is the quality of the coarse aggregate that accounts for the percentage of total quality of the asphalt mixture.

From the inequality criterion $\left(\mathrm{VCA}_{\text {mix }} \leq \mathrm{VCA}_{\mathrm{DRC}}\right)$ of the skeleton structure, it can be seen that the current evaluation parameter is very rough and simple. An inequality is used as the evaluation criterion of skeleton, and it is actually a qualitative rather than a quantitative evaluation criterion. In addition, $\mathrm{VCA}_{\text {mix }}$ is the percent of voids in the coarse mineral aggregate in the asphalt mixture, while $\mathrm{VCA}_{\mathrm{DRC}}$ is the percent of voids in the coarse mineral aggregate in the dry-rodded condition, and there are great differences between the two methods when making specimens and calculating their volume parameter. When calculating $\mathrm{VCA}_{\text {mix }}$ with the empirical method prescribed in the code, it is likely that the calculation results will have errors owing to factors such as the value of empirical coefficients and the accumulation of artificial errors, leading to a mixture gradation that cannot be evaluated objectively and effectively.

3.2. VCA mix Computing Method and Its Optimisation Based on DIP. When calculating $\mathrm{VCA}_{\text {mix }}$ with empirical formulas, many unfavourable factors may lead to large errors in the calculation results. Some studies propose the $\mathrm{VCA}_{\text {mix }}$ measurement based on DIP. This calculation does 


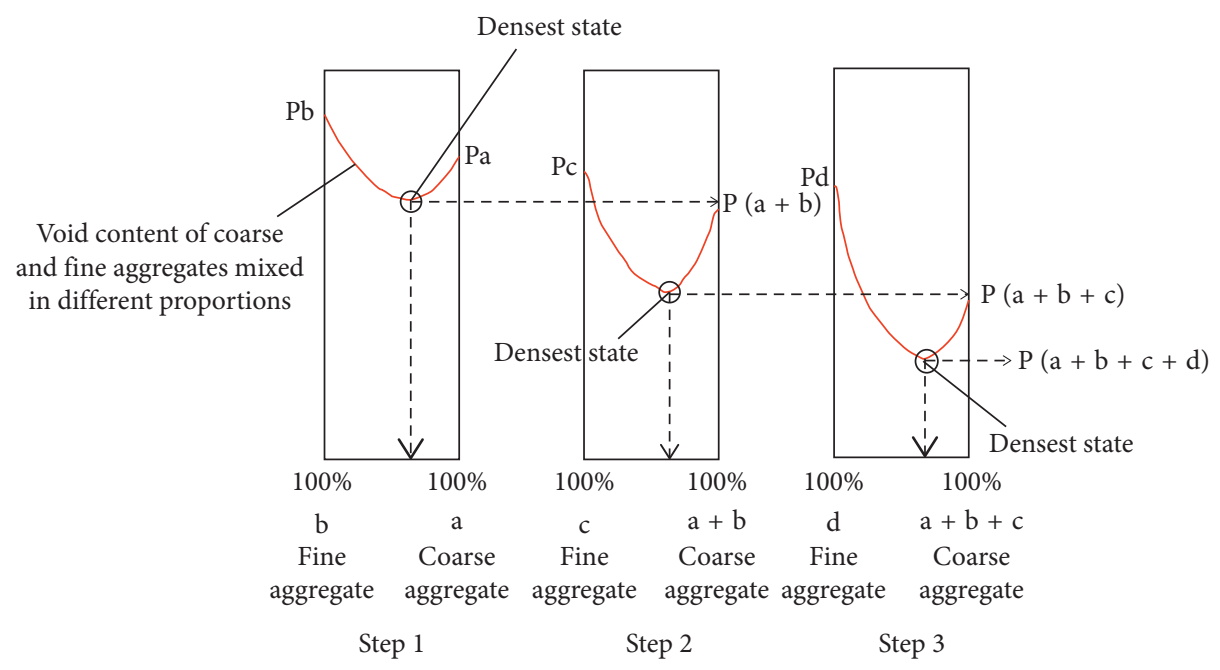

Figure 2: Mixing process of multi-particle-size aggregate.

not involve intermediate variables such as bulk specific gravity and amount of adsorbed asphalt and has achieved good results. The calculation method is expressed in the following equation $[29,30]$ :

$$
\mathrm{VCA}_{\text {mix }}(\mathrm{IMAGE})=\left(1-\frac{M}{N}\right) \times 100,
$$

where $\mathrm{VCA}_{\text {mix }}$ (IMAGE) is the percent of voids in the coarse mineral aggregate in the asphalt mixture calculated by DIP; $M$ is the pixel area of all coarse aggregates in the image; and $N$ is the pixel area of the whole two-dimensional image. The value of $M$ can be obtained by MATLAB software or image processing software, such as IMAQ.

Through a contact analysis, it is found that some coarse aggregates in asphalt mixtures do not contact other coarse aggregates, and those "suspended" in the asphalt mortar do not participate in the formation of the main skeleton. Therefore, the coarse aggregate in the mixture is divided into two parts: the coarse aggregate that participates and the coarse aggregate that does not participate in the main skeleton [24]. The coarse aggregates that do not participate in the main skeleton do not participate in the transmission of skeleton stress. They actually fill the voids within the main skeleton in asphalt mixtures and act as fine aggregates. This part of coarse aggregates should be deducted when calculating $\mathrm{VCA}_{\text {mix }}$, and the improved $\mathrm{VCA}_{\text {mix }}$ calculation method is presented in the following equation [31]:

$$
\mathrm{VCA}_{\text {mix }}(\mathrm{IMAGE})=\left(1-\frac{M-m}{N}\right) \times 100 \text {, }
$$

where the meaning of the parameters $\operatorname{VCA}_{\text {mix }}$ (IMAGE), $M$, and $N$ is the same as in equation (2), and $m$ is the area of coarse aggregate pixels that do not form the skeleton in the image.

As the coarse aggregates that do not participate in the main skeleton are deducted, the $\operatorname{VCA}_{\text {mix }}$ (IMAGE) value calculated by equation (3) is larger than that calculated by the conventional method. Then, the use of $\mathrm{VCA}_{\text {mix }}$ (IMAGE) $\leq \mathrm{VCA}_{\mathrm{DRC}}$ for skeleton discrimination is more stringent, better reflects the characteristics of the main skeleton, and ensures that coarse aggregates are interlocked with each other to form a skeleton. Whether or not the coarse aggregate participate in the formation of the main skeleton can be determined according to the contact analysis.

\subsection{Quantitative Meso Evaluation Parameter and Criterion} for Skeleton. As the only criterion of the main skeleton, $\mathrm{VCA}_{\text {mix }} \leq \mathrm{VCA}_{\mathrm{DRC}}$ distinguishes the main skeleton from the macroscopic and qualitative point of view, but the spatial distribution of aggregate in the asphalt mixture is unknown. Therefore, the following mesoscopic quantitative evaluation parameters are used to evaluate the interlocked characteristics of the main skeleton.

3.3.1. Average Coordination Number. As one of the main factors affecting the stress transfer, strength, and deformation properties of materials, the coordination number is defined as the number of contact points between a particle in the aggregate and its adjacent particles. It is an important mesostructure parameter reflecting the accumulation and mesomechanical behaviour of granular materials [32]. For the asphalt mixture skeleton, the greater the number of contact points around the coarse aggregate and the more uniform their distribution, the better is the stability of aggregate particles under load, as shown in Figure 3.

The average coordination number is defined as the average contact number of the particles in the particle system. The calculation method is shown in the following equation:

$$
\bar{n}_{\mathrm{c}}=\frac{1}{N} \sum_{i=1}^{N} n_{\mathrm{c}}^{i},
$$

where $\bar{n}_{\mathrm{c}}$ is the average coordination number of the asphalt mixture; $N$ is the total quantity of coarse aggregates in the asphalt mixture; and $n_{\mathrm{c}}^{i}$ is the coordination number of coarse aggregate $i$. 


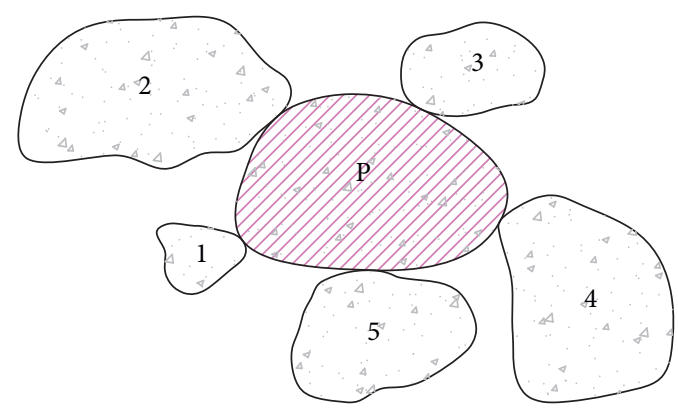

(a)

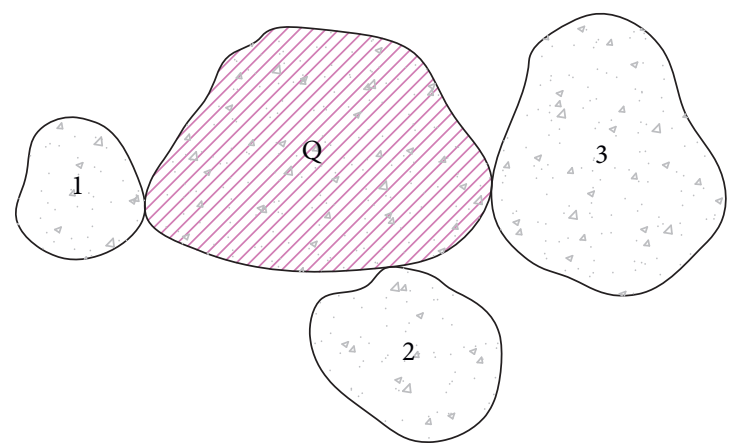

(b)

Figure 3: Diagram of coarse aggregate coordination number: (a) stable particle P and (b) unstable particle Q.

3.3.2. C Value of the "Suspended" Coarse Aggregate Content. In the design process of the DSAM, the amount of fine aggregate should be appropriate and the main skeleton should not be interfered by excessive fine aggregate, and thus, the "suspended" coarse aggregate content should be as small as possible. The "suspended" coarse aggregate content $C$ is the ratio of the quantity of coarse aggregate without contact point to the total quantity of coarse aggregate. The calculation method is expressed in the following equation:

$$
C=\frac{n}{N}
$$

where $N$ and $n$ are the total number of coarse aggregates in the asphalt mixture and the number of coarse aggregates without contact points, respectively.

3.3.3. Criterion for Meso Evaluation Parameter. According to the author's statistical analysis of the mesostructural characteristics of the main skeleton of different asphalt mixtures [33], by adjusting the gradation to increase the average coordination number and reduction of the $C$ value, the meso parameter of the mixture can be effectively improved, and the quality of the main skeleton can be considerably improved. The qualitative and quantitative evaluation criterion of the optimal main skeleton formed by coarse aggregates is $\mathrm{VCA}_{\text {mix }}(\mathrm{IMAGE}) \leq \mathrm{VCA}_{\mathrm{DRC}}$ and $\bar{n}_{\mathrm{c}}>1.6$ while $C<20 \%$. The evaluation criterion is derived from [33] and verified by tests, which can ensure that coarse aggregates interlocked each other to form a more stable skeleton structure. This study evaluates the designed skeleton performance of the asphalt mixture by using this evaluation criterion and puts forward the process and fine design method for designing DSAMs based on meso parameter.

3.4. Image Processing and Contact Analysis Method. Image processing and contact analysis procedures are carried out according to the method proposed in a previous study $[24,34]$. The asphalt mixture image taken by digital camera is processed and analyzed by the MATLAB software. It is found that the gray histogram distribution curve has distinct "double-peak" characteristics. Therefore, the gray value demarcation points $\left(T_{1}\right.$ and $\left.T_{2}\right)$ of voids, asphalt binders, and aggregates can be determined according to gray histogram distribution curve, and the image can be binarized using the double-peak method by the MATLAB software. Then, a watershed algorithm can be used for image segmentation if some coarse aggregates adhere to each other after the image binarisation, as shown in Figure 4.

After the image binarisation is completed, the contact analysis is performed using iPas software, designed by Prof. Hussain Bahia of the University of Wisconsin-Madison and Prof. M. Emin Kutay of Michigan State University [34]. The main steps are as follows: input parameters such as raw materials, volume indices, and gradation of asphalt mixture; iPas software will obtain the equivalent diameter of each coarse aggregate according to the equivalent diameter method, to get the gradation in the image. In this process, the gradation in the image is consistent with the actual asphalt mixture gradation by setting appropriate parameters. After the calculated minimum particle size and surface distance threshold (SDT) value are inputted, iPas software numbered each coarse aggregate and quantified the coarse aggregate contact details, such as contact point location, number and particle size of contact aggregates, and quantity of contact points. Thereafter, the coordination number $\bar{n}_{\mathrm{c}}$ and $C$ value can be obtained by statistical analysis of the number and particle size of the coarse aggregates and the quantity of contact points around each coarse aggregate, i.e., as shown in Figure 5 .

The SDT value is related to the calculated minimum particle size of aggregates. Existing studies show that SDT value is generally $0.20-0.25$ times of the calculated minimum particle size of aggregates $[35,36]$. Therefore, the minimum calculated particle size of aggregates is 0.23 times SDT value in the test. Because the minimum particle size is $2.36 \mathrm{~mm}$, the SDT value is set to $0.54 \mathrm{~mm}$.

\section{New Method for Designing DSAM Based on Meso Evaluation Parameter}

According to the analysis results of the previous sections, in the process of designing a DSAM by the multilevel mixing method, owing to various reasons, it is unknown whether the final gradation curve of asphalt mixture is interfered or 

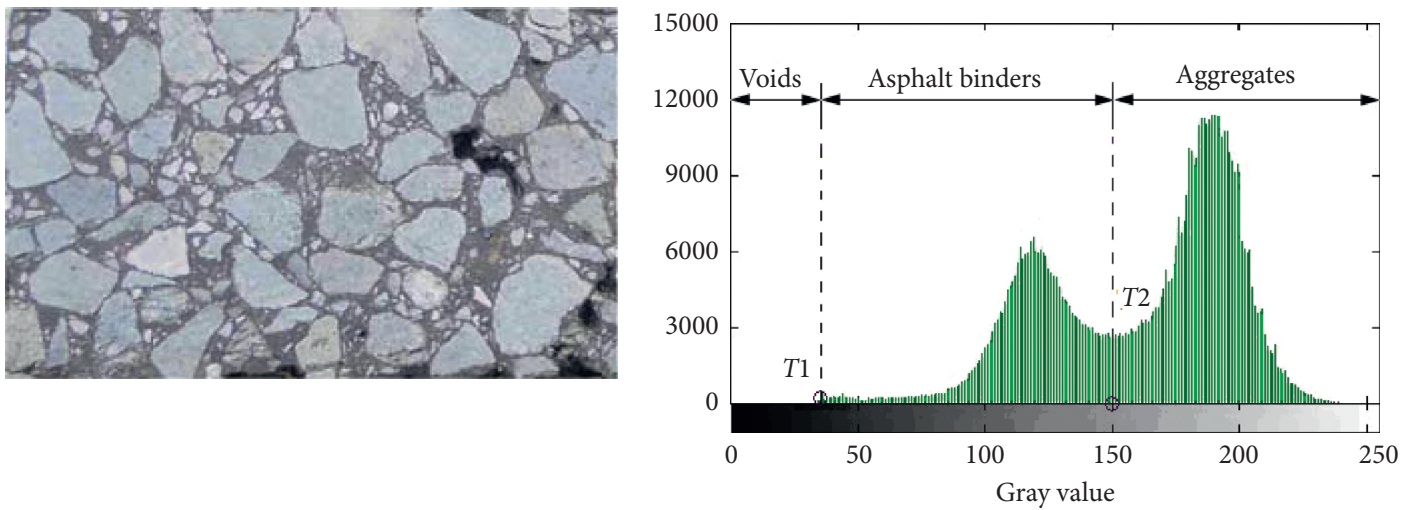

(a)

(b)

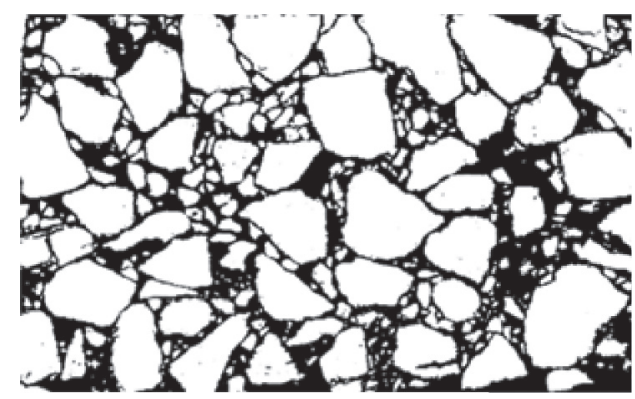

(c)

FIGURE 4: Image processing: (a) original image; (b) gray histogram; (c) binary image (reproduced from Shi et al. [12]).

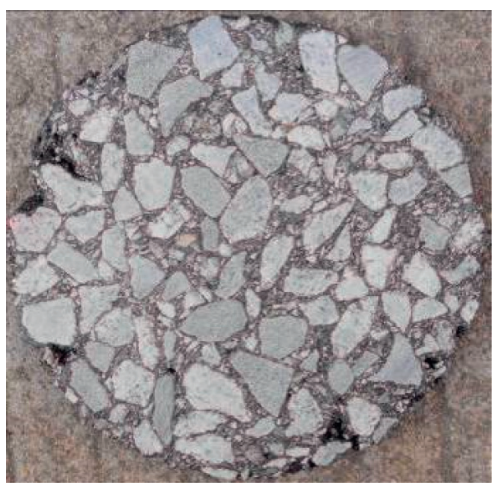

(a)

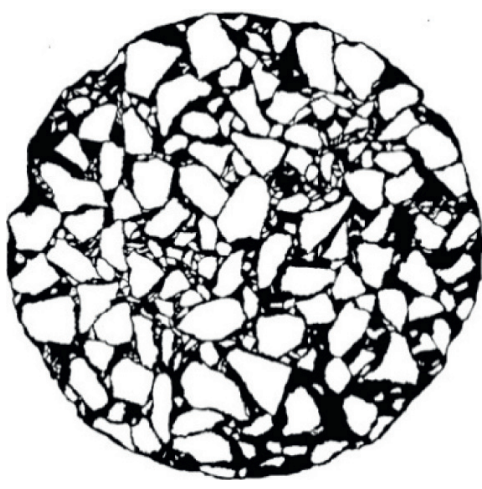

(b)

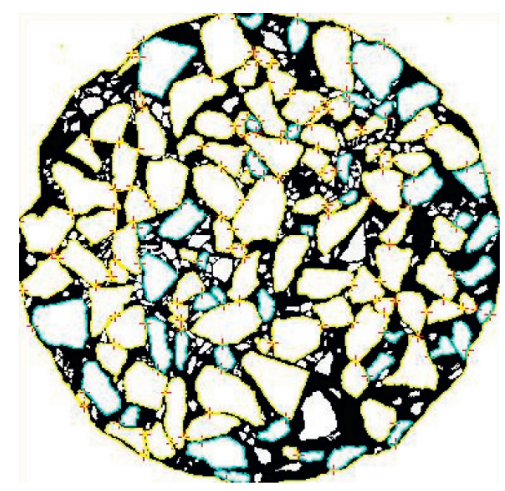

(c)

FIGURE 5: Image processing and contact analysis: (a) section image of HMA; (b) binary image; (c) contact analysis results.

not and whether the coarse aggregate is fully embedded to obtain a better skeleton structure. Therefore, a new method of designing a DSAM based on meso parameter is proposed in this study, which ensures that coarse aggregates are interlocked to form the main skeleton and fine aggregates fill the voids of the skeleton formed by the coarse aggregates. The whole design process is intuitive, visual, and operable. The procedure is as follows.

4.1. First Step: Divide the Aggregate into Two Parts-Coarse and Fine Aggregates. The purpose is to distinguish the role of each structural component in the mixture to ensure that coarse aggregates are interlocked to form the main skeleton and fine aggregates fill the voids of the skeleton formed by the coarse aggregates.

4.2. Second Step: Design the Main Skeleton by the Multilevel Mixing Method. Starting with the nominal maximum particle size, taking the aggregate with larger particle size as the coarse aggregate and the aggregate with smaller particle size as the fine aggregate, dry tamping tests are carried out according to mixing proportions of coarse and fine aggregates of $0: 100,20: 80,40: 60,60: 40,80: 20$, and $100: 0$, respectively. At least three parallel tests are carried out for 
each ratio, and the percentage of voids is measured and fitted by Gauss peak fitting. The minimum value of the percentage of voids is the optimal skeleton ratio constituted by coarse and fine aggregates. At the same time, to verify whether the main skeleton is interfered or not, skeleton discrimination is required according to equation (6). If the verification results show that the skeleton is interfered, it is necessary to adjust the ratio of coarse to fine aggregate to meet the requirements of equation (6). The coarse aggregate gradation curve can be obtained according to the order of aggregate size, from large to small:

$$
\left\{\begin{array}{l}
q_{\mathrm{c}}+q_{\mathrm{f}}=100, \\
\frac{q_{\mathrm{c}}}{100 \rho_{\mathrm{sc}}} V C A>\frac{q_{\mathrm{f}}}{\rho_{\mathrm{f}}},
\end{array}\right.
$$

where $q_{\mathrm{c}}$ and $q_{\mathrm{f}}$ are the contents of coarse and fine aggregates, respectively; VCA is the void ratio of coarse aggregate in the dry tamping test; and $\rho_{\mathrm{sc}}$ and $\rho_{\mathrm{f}}$ are the coarse aggregate dry tamping density and fine aggregate bulk density, respectively.

\subsection{Third Step: Determine the Fine Aggregate Gradation.} During the mixing process, the fine aggregate tends to segregate owing to its smaller particle size, resulting in a large variation of test results. Because the fine aggregate mainly plays the role of filling the voids of the skeleton formed by the coarse aggregates, it simply does not interfere with the main skeleton. Thus, the fine aggregate is not involved in the mixing, and the gradation only needs to meet the functional requirements of compaction. Considering that Talbot's maximum density curve ( $n$ method, $n=0.435$ ) is adopted in the Superpave gradation design method, the mixture can obtain higher temperature stability when the gradation curve dips below the forbidden zone. Therefore, this study recommends the grading curve below the restricted area.

\subsection{Fourth Step: Determine the Ratio of Coarse to Fine Ag-} gregate and the Initial Asphalt Content. The key point of DSAM design is making the coarse aggregate to form the optimal main skeleton because the mineral powder-to-asphalt ratio has little effect on the gradation and, according to the results of relevant studies, the value of the mineral powder-to-asphalt ratio is 1.3 [37]. The amount of mineral powder is determined according to the recommended value of the Superpave design method. The percentages of the maximum nominal particle sizes of $26 \mathrm{~mm}, 19 \mathrm{~mm}$, and less than $13.2 \mathrm{~mm}$ are $1-7 \%, 2-8 \%$, and $2-10 \%$, respectively. Therefore, the ratio of coarse to fine aggregate and the initial asphalt content can be determined according to the following equation:

$$
\left\{\begin{array}{l}
q_{\mathrm{c}}+q_{\mathrm{f}}+q_{\mathrm{m}}+q_{\mathrm{a}}=100, \\
\frac{q_{\mathrm{c}}}{100 \rho_{\mathrm{dc}}}\left(V C A_{\mathrm{DRC}}-V V\right)=\frac{q_{\mathrm{f}}}{\rho_{\mathrm{df}}}+\frac{q_{\mathrm{m}}}{\rho_{\mathrm{m}}}+\frac{q_{\mathrm{a}}}{\rho_{\mathrm{a}}},
\end{array}\right.
$$

where $q_{\mathrm{c}}, q_{f}, q_{\mathrm{m}}$, and $q_{\mathrm{a}}$ are the mass ratios of coarse aggregate, fine aggregate, mineral powder, and asphalt, respectively; $\rho_{\mathrm{dc}}, \rho_{d f}, \rho_{\mathrm{m}}$, and $\rho_{a}$ are the coarse aggregate dry tamping density, fine aggregate bulk density, mineral powder density, and asphalt density, respectively; $\mathrm{VCA}_{\mathrm{DRC}}$ denotes the voids in the coarse aggregate obtained in the second step of the design process; and $V V$ denotes the designed voids in the mineral aggregate.

4.5. Fifth Step: Verification of the Optimal Main Skeleton and Detailed Adjustment of Gradation. The ratio of each coarse aggregate is obtained by theoretical calculation. It is still necessary to verify whether the main skeleton is interfered after mixing the fine aggregate, mineral powder, and asphalt, which is also the key to ensure that the coarse aggregates are interlocked to form the optimal main skeleton. In the design process, the contact characteristics of the coarse aggregate in the asphalt mixture are analyzed by DIP, and the interference degree and interlocking effect of the main skeleton are evaluated after obtaining the meso evaluation parameter, and the design gradation is adjusted and optimised accordingly.

The specific procedure is as follows: the Marshall specimen (double-sided compaction, 75 times) or the Superpave gyratory compactor (SGC) specimen (rotating compaction, 150 times) is made according to the gradation designed in the fourth step; the section images were acquired using X-ray CT scanning or photographs by CCD digital camera after cutting the specimen. Then, image processing and coarse aggregate contact analysis are carried out, obtaining the meso evaluation parameters such as VCAmix (IMAGE), average coordination number $\bar{n}_{c}$, and "suspended" coarse aggregate content $C$; after that, the designed gradation is verified or adjusted according to the evaluation parameter. The qualitative and quantitative evaluation criterion of the optimal main skeleton formed by coarse aggregates is $\mathrm{VCA}_{\text {mix }}(\mathrm{IMAGE}) \leq \mathrm{VCA}_{\mathrm{DRC}}$ and $\bar{n}_{\mathrm{c}}>1.6$ while $C<20 \%$ [33]. In this study, the designed HMA skeleton performance is evaluated by this evaluation criterion.

As for the number of the two-dimensional section image of the mixture, at least three Marshall or SGC specimens should be made to obtain more than 20 two-dimensional section images, achieving an error of engineering accuracy of less than $5 \%$. The verification of the optimal main skeleton and detailed adjustment of the gradation are carried out under the condition of visualisation by DIP, which not only is intuitive and convenient, but also has higher precision and demands less test work.

4.6. Sixth Step: Determine the Optimal Asphalt Content. In the fourth step of the design process, the initial asphalt content is determined by calculating when the ratio of powder to binder is $1: 3$. After the detailed adjustment of gradation, the asphalt content will change slightly, and the final optimal asphalt content can be determined by the Marshall test. With this step, the whole design process of the DSAM is completed. The flowchart of the design process is presented in Figure 6. 


\section{Design Example and Engineering Application}

In this section, the proposed new design method proposed is used to design a DSAM. After obtaining the skeleton dense gradation, three different asphalt binders, 70\# asphalt, UM rock asphalt (with mixing amount of $8 \%$ ), and SBS-modified asphalt, are selected to compare and analyse the pavement performance of the designed asphalt mixtures.

5.1. Test Materials. The coarse aggregate used in the test is granite and the fine aggregate is limestone. The technical properties of the coarse aggregate are presented in Table 1. The density of the coarse aggregates in each grade is the key parameter in the design process, which was measured using the volumetric flask method. The density of each material is listed in Table 2 . The properties of the 70\# asphalt, UM rock asphalt (with mixing amount of $8 \%$ ), and SBS-modified asphalt are listed in Table 3 and 4 . All the technical indicators of the test materials meet the requirements of the code [38].

5.2. Gradation Design of Asphalt Mixture. In this section, the proposed new design method is used to design a DSAM. The process is as follows.

5.2.1. First Step: Divide the Aggregate into Two Parts-Coarse and Fine Aggregates. The boundary of the coarse and fine aggregates was determined. The boundary of the coarse and fine aggregates of the asphalt mixture in this study was $2.36 \mathrm{~mm}$ for a maximum nominal particle size of $13.2 \mathrm{~mm}$. There were three mixing stages in the main skeleton design: the first stage comprised mixing $13.2 \mathrm{~mm}$ aggregate with $9.5 \mathrm{~mm}$ aggregate; the second stage comprised mixing the coarse aggregate $(13.2 \mathrm{~mm}+9.5 \mathrm{~mm})$ blend from the first stage with $4.75 \mathrm{~mm}$ aggregate; and the third stage involved mixing the blend of coarse aggregate $(13.2 \mathrm{~mm}+9.5 \mathrm{~mm}+$ $4.75 \mathrm{~mm}$ ) with $2.36 \mathrm{~mm}$ aggregate.

5.2.2. Second Step: Design the Main Skeleton by the Multilevel Mixing Method. The multilevel mixing is designed using the dry tamping test. It is considered that the process of aggregate tamping may easily shatter the aggregates and make them scatter, affecting the accuracy of the test. Therefore, in the process of tamping, after the mixture is put into the measuring cylinder, the mixture is covered with the iron cover and the tamping rod is directly tampered on the iron cover. According to the symmetrical distribution, four points at the circumference and one point at the centre of the circle are selected to measure the height, and the mean value is taken as the final tamping height. Starting from the 16$13.2 \mathrm{~mm}$ and $13.2-9.5 \mathrm{~mm}$ aggregates, the aggregate was mixed according to the order of particle size, from large to small. Dry tamping tests were carried out according to mixing proportions of coarse and fine aggregates of $0: 100$, $20: 80,40: 60,60: 40,80: 20$, and 100:0, respectively, and the percentage of voids was measured and fitted by Gauss peak fitting. Then, the optimal skeleton ratio constituted by

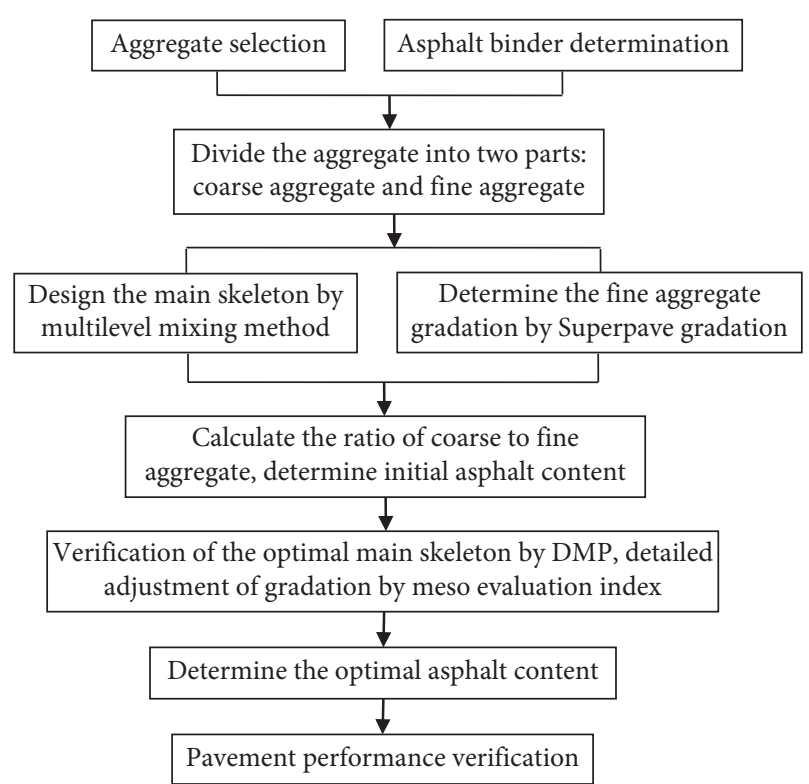

FIgURE 6: Design flowchart of DSAM.

TABle 1: Properties of coarse aggregate.

\begin{tabular}{lcc}
\hline Test indicators & Requirements & $\begin{array}{c}\text { Test } \\
\text { result }\end{array}$ \\
\hline Crushed stone value (\%) & $\leq 26$ & 13.5 \\
Los Angeles abrasion value (\%) & $\leq 28$ & 24 \\
Apparent specific density $\left(\mathrm{g} / \mathrm{cm}^{3}\right)$ & $\geq 2.60$ & $>2.67$ \\
Water absorption (\%) & $\leq 2.0$ & 0.75 \\
Flat and elongated particle content (\%) & $\leq 15$ & 8.6 \\
Particle size $\geq 9.5 \mathrm{~mm}(\%)$ & $\leq 12$ & 7.5 \\
Particle size $<9.5 \mathrm{~mm}(\%)$ & $\leq 18$ & 10.2 \\
Content of particles $<0.075 \mathrm{~mm}(\%)$ & $\leq 1$ & 0.7 \\
\hline
\end{tabular}

coarse and fine aggregates is obtained. The results of the coarse aggregate mixing and percentage of voids fitting are shown in Figure 7.

It should be noted that, although the minimum percentage of the void fitting curve in Figure 7 is the proportion of coarse and fine aggregates in the densest state, a skeleton discrimination still needs to be made according to equation (6) in the design process to verify whether the aggregate skeleton is interfered and obtain the optimal coarse aggregate mixing results, as presented in Table 5 .

Now, the mixing design process of coarse aggregate is complete and the dry compaction density of the synthesised mixture is calculated to be $1.668 \mathrm{~g} / \mathrm{cm}^{3}$, and $\mathrm{VCA}_{\mathrm{DRC}}$ is $37.53 \%$. The mixing ratio of coarse aggregate for each grade is as follows: $13.2 \mathrm{~mm}-16 \mathrm{~mm}: 9.5 \mathrm{~mm}-13.2 \mathrm{~mm}: 4.75 \mathrm{~mm}-$ $9.5 \mathrm{~mm}: 2.36 \mathrm{~mm}-4.75 \mathrm{~mm}=21.49: 15.82: 25.29: 37.4$. That is, the ratio of aggregate for each grade is $1: 0.74: 1.17: 1.74$, in the order of aggregate size from large to small.

5.2.3. Third Step: Determine the Fine Aggregate Gradation. On the basis of the Superpave gradation design method, the fine aggregate gradation is selected in the grading curve below the restricted area, so the aggregate ratio for each 
TABle 2: Density of each material.

\begin{tabular}{lcccccccc}
\hline Materials & \multicolumn{7}{c}{ Apparent specific density $\left(\mathrm{g} / \mathrm{cm}^{3}\right)$} \\
\hline & 13.2 & 9.5 & 4.75 & 2.36 & 1.18 & 0.6 & 0.3 & 0.15 \\
Aggregate $(\mathrm{mm})$ & 2.698 & 2.707 & 2.715 & 2.704 & 2.725 & 2.719 & 2.723 & 2.725 \\
Cement & & & & & 3.02 & & & \\
\hline
\end{tabular}

Table 3: Properties of UM asphalt.

\begin{tabular}{lcc}
\hline Test indicators & Requirements & Test result \\
\hline Appearance & Black powder & Black powder \\
Ash content $(\%)$ & $\leq 20$ & 12 \\
Asphalt content $(\%)$ & $\geq 70$ & 88 \\
Specific density $\left(\mathrm{g} / \mathrm{cm}^{3}\right)$ & 0.75 & 0.765 \\
Water content $(\%)$ & $\leq 1$ & 1.28 \\
Granularity $(0.075$ passing rate) $(\%)$ & - & 32.4 \\
\hline
\end{tabular}

TABle 4: Properties of asphalt.

\begin{tabular}{lccc}
\hline Test indicators & & Test result \\
& 70\# asphalt & UM rock asphalt & SBS-modified asphalt \\
\hline Penetration $\left(25^{\circ} \mathrm{C}, 100 \mathrm{~g}, 5 \mathrm{~s}\right) / 0.1 \mathrm{~mm}$ & 66 & 63 & 62 \\
Ductility $\left(5 \mathrm{~cm} / \mathrm{min}, 15^{\circ} \mathrm{C}\right)(\mathrm{cm})$ & 135 & 138 & 147 \\
Softening point $\left({ }^{\circ} \mathrm{C}\right)$ & 50.0 & 70 & 79.0 \\
Density $\left(15^{\circ} \mathrm{C}\right)\left(\mathrm{g} / \mathrm{cm}^{3}\right)$ & 1.058 & 1.043 & 1.033 \\
\hline
\end{tabular}

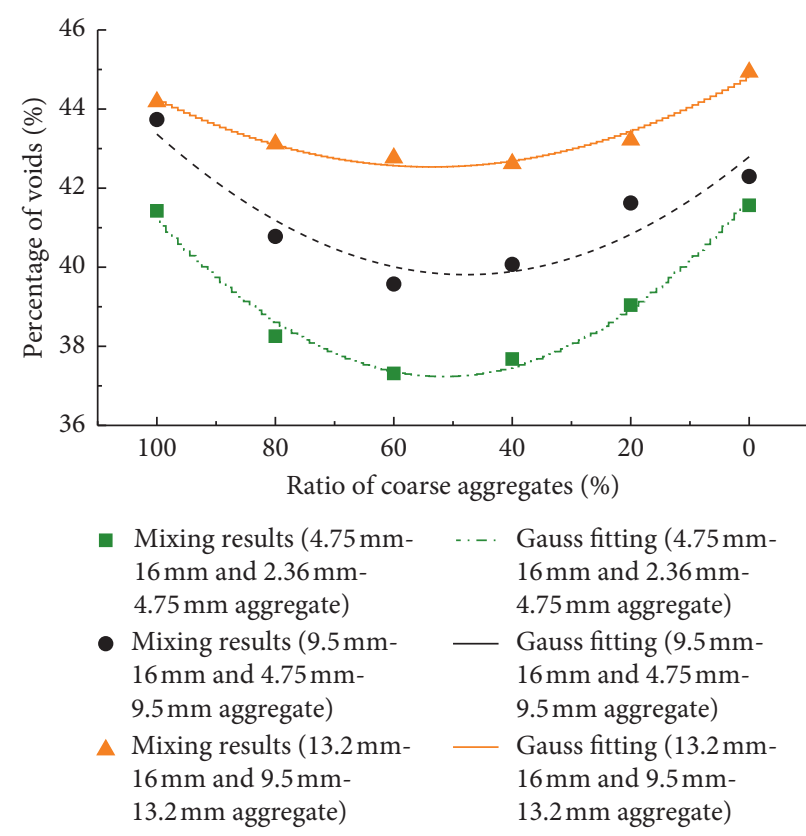

Figure 7: Percentage of void fitting results.

grade is as follows: $1.18 \mathrm{~mm}: 0.6 \mathrm{~mm}: 0.3 \mathrm{~mm}: 0.15 \mathrm{~mm}$ : $0.075 \mathrm{~mm}=41.9: 22.1: 12.3: 7.9: 15.8$, and the synthetic density is $2.725 \mathrm{~g} / \mathrm{cm}^{3}$.

5.2.4. Fourth Step: Determine the Ratio of Coarse to Fine Aggregate and the Initial Asphalt Content. The designed void ratio in the mixture is $4 \%$. To improve the adhesion of granite, the initial cement content is $2 \%$ and the initial asphalt content is $4.8 \%$. The proportion of the mixture calculated by equation (7) is $q_{\mathrm{c}}: q_{\mathrm{f}}: q_{\mathrm{a}}: q_{\mathrm{m}}=67.8$ : $23.4: 4.8: 2.0$.

5.2.5. Fifth Step: Verification of the Optimal Main Skeleton and Detailed Adjustment of Gradation. The verification of the optimal skeleton and the detailed adjustment of gradation are the most important steps in the design process of 
TABle 5: Optimal coarse aggregate mixing results.

\begin{tabular}{lcc}
\hline Mixing process & $\begin{array}{c}\text { Mixing proportion with smallest } \\
\text { percentage of voids (\%) }\end{array}$ & $\begin{array}{c}\text { Final mixing proportion } \\
\text { after adjustment (\%) }\end{array}$ \\
\hline Mixing of $13.2 \mathrm{~mm}$ and $9.5 \mathrm{~mm}$ & $53.5: 46.5$ & $57.6: 42.4$ \\
Mixing of $13.2 \mathrm{~mm}-9.5 \mathrm{~mm}$ and $4.75 \mathrm{~mm}$ & $47.5: 52.5$ & $59.6: 40.4$ \\
Mixing of $13.2 \mathrm{~mm}-4.75 \mathrm{~mm}$ and $2.36 \mathrm{~mm}$ & $51.5: 48.5$ & $62.6: 37.4$ \\
\hline
\end{tabular}

the main skeleton and ensure the formation of the optimal main skeleton of coarse aggregate. Marshall specimens (double-sided compaction, 75 times) were made according to the gradation of the preliminary design. The specimens were cut, and asphalt mixture section images were obtained for image processing and coarse aggregate contact analysis. The results show that $\operatorname{VCA}_{\text {mix }}(\mathrm{IMAGE})=38.31 \%, \bar{n}_{c}=1.51$, and $C=22 \%$. Because the meso evaluation parameters could not meet the skeleton discrimination requirements of $\mathrm{VCA}_{\text {mix }}$ (IMAGE) $<\mathrm{VCA}_{\mathrm{DRC}}$, and the value $\bar{n}_{\mathrm{c}}$ is less than 1.6 , it is necessary to adjust the proportion of coarse and fine aggregates.

After two times adjusted gradation, $\mathrm{VCA}_{\text {mix }}(\mathrm{IMAGE})=$ $36.47 \%, \bar{n}_{\mathrm{c}}=1.69$, and $C=20 \%$ were obtained by contact analysis after adding an appropriate content of 4.75$16.0 \mathrm{~mm}$ coarse aggregate, indicating that the coarse aggregate has formed a better skeleton, as shown in Figure 8. At this time, the ratio of each component in mixture is $q_{\mathrm{c}}: q_{\mathrm{f}}: q_{\mathrm{a}}: q_{\mathrm{m}}=68.9: 24.3: 4.8: 2.0$. The gradation of asphalt mixture can be calculated according to the ratio of each component in mixture, the optimal skeleton ratio constituted by coarse aggregates in the second step, and the ratio of fine aggregate in the third step. The designed asphalt mixture gradation is presented in Table 6. Before and after gradation adjustment, the coordination number distribution of the coarse aggregate and the average coordination number of the asphalt mixture are obtained through contact analysis, as listed in Table 7, and the fitting curve of the coordination number is shown in Figure 9.

According to Table 7 and Figure 9, the coarse aggregate content with larger coordination number increases after the gradation is adjusted. The meso performance of the adjusted gradation is that the coordination number of the coarse aggregate increases while the average coordination number of the mixture increases. The maximum value of the coarse aggregate coordination number is 5 . Coarse aggregate with coordinate number 2 is the most abundant, and its content accounts for about $32 \%$ of the total amount of coarse aggregate, showing the peak value of the coordinate number distribution of coarse aggregate. The distribution of coarse aggregate coordination numbers in the asphalt mixture is in agreement with the Gauss distribution.

5.2.6. Sixth Step: Determine the Optimal Asphalt Content. The final step of the design is to determine optimal asphalt content according to the Marshall test, and the test results are presented in Table 8 . The results show that the optimal asphalt aggregate ratio is $5 \%$. With this step, the whole design process of the asphalt mixture has been completed.
5.3. Analysis of Asphalt Mixture Pavement Performance. In order to compare the antirutting performance of the asphalt mixture before and after gradation adjustment, SBSmodified asphalt mixture specimens were prepared for rutting test. The average results are shown in Table 9.

According to the gradation design presented in Table 8, the pavement performance of asphalt mixtures with 70\# asphalt, UM rock asphalt (with mixing amount of $8 \%$ ), and SBS-modified asphalt are tested and compared according to the specifications [37]. The results are listed in Table 10.

By analysing the design process of the asphalt mixture, data in Tables 10, the main conclusions are as follows:

(1) By adjusting the gradation to increase the average coordination number and reduce the $C$ value, the meso parameter of the mixture can be effectively improved, and the quality of the main skeleton can be considerably improved. According to the asphalt mixture designed based on the meso parameter has excellent pavement performance, including hightemperature stability, water stability, and low-temperature stability. The dynamic stability of the $70 \#$ asphalt mixture is close to the modified asphalt dynamic stability requirement. The stability of the main skeleton in the mixture is better, and the antirutting performance is considerably improved.

(2) The rutting resistance of the asphalt mixture can be significantly improved using a higher performance asphalt binder to restrain the main skeleton. The dynamic stability of the asphalt mortar with $8 \% \mathrm{UM}$ rock asphalt or SBS-modified asphalt is almost doubled, compared with the 70\# asphalt mixture.

\section{Conclusions}

Based on an in-depth analysis of the existing evaluation parameters and standards for the asphalt mixture skeleton, a new precise design method of DSAMs based on meso parameter is proposed in this study. The main conclusions are as follows:

(1) The application of DIP to verify and adjust in detail the main skeleton of the asphalt mixture can effectively avoid the segregation problem in the process of fine aggregate grade mixing. The process is carried out under the condition of visualisation, which not only is intuitive and convenient, but also has higher precision and demands less test work. The meso parameters obtained by DIP, including average coordination number $\bar{n}_{\mathrm{c}}$ and $C$ value of "suspended" coarse aggregate content, can be used as the quantitative meso evaluation parameter of the main 


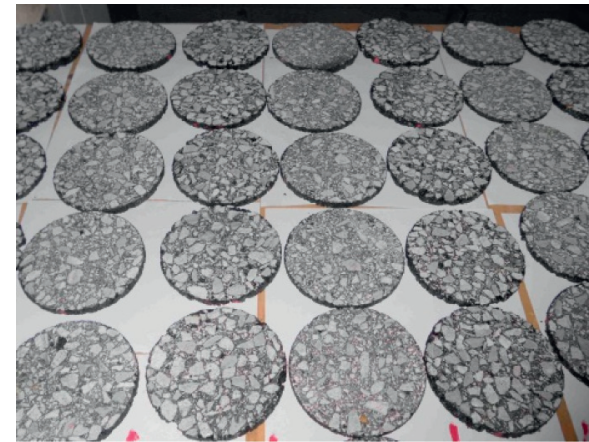

(a)

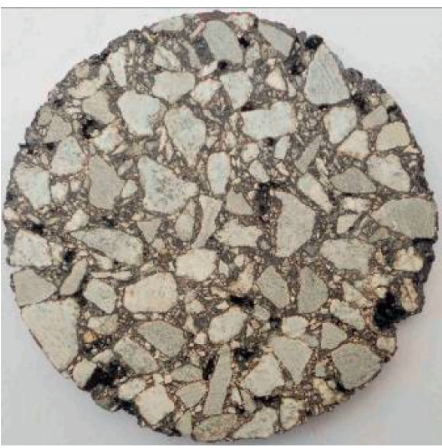

(b)

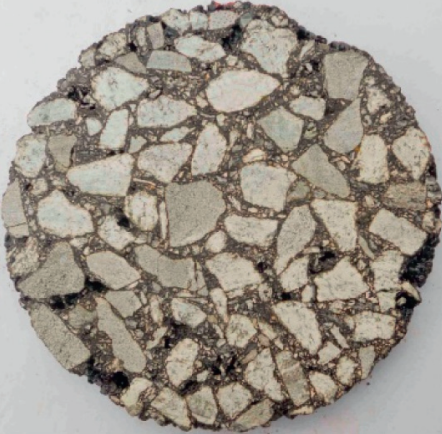

(c)

FIGURE 8: Comparison of Marshall section images: (a) section images; (b) before adjusted gradation; (c) second adjusted gradation.

TABLE 6: Designed gradation of asphalt mixture.

\begin{tabular}{|c|c|c|c|c|c|c|c|c|c|c|}
\hline \multirow{2}{*}{ Gradation } & \multicolumn{10}{|c|}{ Passing rate $(\%)$} \\
\hline & 16 & 13.2 & 9.5 & 4.75 & 2.36 & 1.18 & 0.6 & 0.3 & 0.15 & 0.075 \\
\hline AC-13 & 100 & 99.5 & 75.9 & 40.3 & 31.4 & 23.5 & 16.5 & 9.8 & 6.7 & 4.3 \\
\hline
\end{tabular}

TABLE 7: Coordination number distribution of coarse aggregate.

\begin{tabular}{|c|c|c|c|c|c|c|c|c|}
\hline \multirow{3}{*}{ Gradation types } & \multirow{3}{*}{ Number of contact points } & \multicolumn{6}{|c|}{ Coordination number distribution of coarse aggregate } & \multirow{3}{*}{$\bar{n}_{\mathrm{c}}$} \\
\hline & & 0 & 1 & 2 & 3 & 4 & 5 & \\
\hline & & \multicolumn{6}{|c|}{$\begin{array}{c}\text { Number of coarse aggregates corresponding to coordination } \\
\text { numbers/particle }(\%)\end{array}$} & \\
\hline Before adjusted & 116 & $24(18.2)$ & $40(30.3)$ & $42(31.8)$ & $19(14.4)$ & $4(3.0)$ & $2(1.5)$ & 1.51 \\
\hline First adjusted & 125 & $18(12.7)$ & $43(30.3)$ & $46(32.4)$ & $24(16.9)$ & $5(3.5)$ & $4(2.8)$ & 1.58 \\
\hline Second adjusted & 128 & $17(11.6)$ & $44(29.9)$ & $46(31.3)$ & $26(17.7)$ & $9(6.1)$ & $6(4.1)$ & 1.69 \\
\hline
\end{tabular}

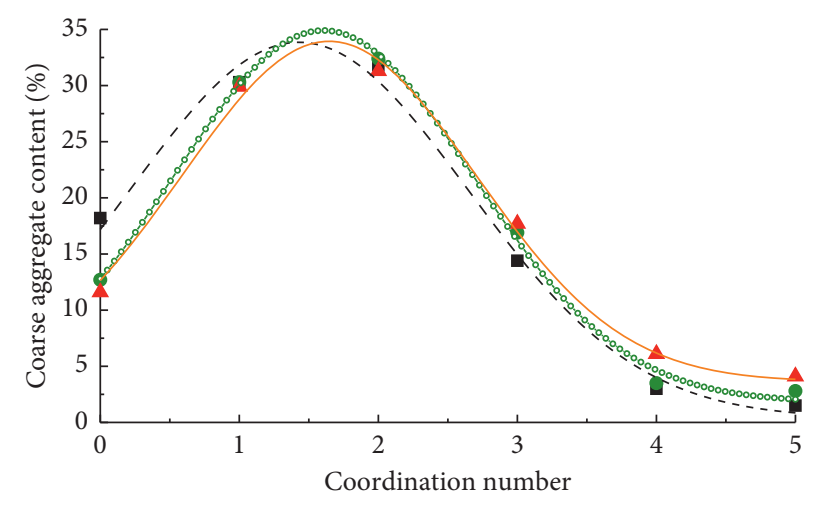

- Before adjusted _ Gauss fitting (before adjusted)

- First adjusted - - - - Gauss fitting (first adjusted)

$\Delta$ Second adjusted _ Gauss fitting (second adjusted)

FIgURE 9: Coordination number distribution.

TABLE 8: Marshall test results.

\begin{tabular}{lccccccc}
\hline $\begin{array}{l}\text { Material } \\
\text { type }\end{array}$ & $\begin{array}{c}\text { Asphalt content } \\
(\%)\end{array}$ & $\begin{array}{c}\text { Specimen density } \\
\left(\mathrm{g} \cdot \mathrm{cm}^{-3}\right)\end{array}$ & $\begin{array}{c}\text { Percent air voids } \\
(\%)\end{array}$ & VMA & VFA & $\begin{array}{c}\text { Marshall stability } \\
(\mathrm{kN})\end{array}$ & $\begin{array}{c}\text { Flow value/ } \\
(0.1 \mathrm{~mm})\end{array}$ \\
\hline & 4.9 & 2.406 & 4.037 & 14.84 & 72.8 & 11.34 & 36.1 \\
AC-13 & 5.2 & 2.404 & 3.332 & 14.76 & 77.5 & 12.48 & 39.3 \\
& 5.5 & 2.419 & 2.094 & 14.22 & 85.3 & 12.83 & 43.9 \\
& Technical requirement & & $3-5$ & $\geq 14.5$ & $65-75$ & $>7.5$ & $20-40$ \\
\hline
\end{tabular}


TABLE 9: Meso parameters and rutting test results before and after gradation optimisation.

\begin{tabular}{|c|c|c|c|c|c|c|}
\hline Gradation types & $\mathrm{VCA}_{\text {mix }}(\mathrm{IMAGE})(\%)$ & Number of contact points & $\bar{n}_{\mathrm{c}}$ & $C(\%)$ & Dynamic stability (times $\cdot \mathrm{mm}^{-1}$ ) & Rut depth $(\mathrm{mm})$ \\
\hline Before adjusted & 38.31 & 116 & 1.51 & 22 & 3566 & 2.756 \\
\hline First adjusted & 37.46 & 125 & 1.58 & 20 & 4565 & 2.622 \\
\hline Second adjusted & 36.47 & 128 & 1.69 & 20 & 4639 & 2.354 \\
\hline
\end{tabular}

TABLe 10: Pavement performance of asphalt mixture.

\begin{tabular}{|c|c|c|c|c|c|c|c|c|c|}
\hline \multirow[b]{2}{*}{ Pavement performance } & \multirow[b]{2}{*}{ Test project } & \multirow[b]{2}{*}{ Test conditions } & \multirow[b]{2}{*}{ Evaluation parameter } & \multicolumn{6}{|c|}{ Test results } \\
\hline & & & & \multicolumn{2}{|c|}{$70 \#$ asphalt } & \multicolumn{2}{|c|}{$\begin{array}{l}\text { UM rock } \\
\text { asphalt }\end{array}$} & \multicolumn{2}{|c|}{$\begin{array}{l}\text { SBS- } \\
\text { modified } \\
\text { asphalt }\end{array}$} \\
\hline High-temperature stability & \multirow{2}{*}{$\begin{array}{l}\text { Rutting test } \\
\text { Immersed }\end{array}$} & \multirow{3}{*}{$\begin{array}{c}60^{\circ} \mathrm{C}, 0.7 \mathrm{MPa} \\
\text { Before immersion }(\mathrm{kN}) \\
\text { After immersion }(\mathrm{kN}) \\
\text { No freeze-thaw }(\mathrm{MPa}) \\
\text { After freeze-thaw }(\mathrm{MPa})\end{array}$} & Dynamic stability (times $\cdot \mathrm{mm}^{-1}$ ) & \multicolumn{2}{|c|}{2351} & \multicolumn{2}{|c|}{4515} & \multicolumn{2}{|c|}{4639} \\
\hline \multirow{3}{*}{$\begin{array}{l}\text { Water stability and } \\
\text { low-temperature } \\
\text { bending test }\end{array}$} & & & Residual stability (\%) & $\begin{array}{l}12.63 \\
10.44\end{array}$ & 82.7 & $\begin{array}{l}16.2 \\
14.1\end{array}$ & 87.1 & $\begin{array}{l}16.7 \\
14.3\end{array}$ & 85.6 \\
\hline & $\begin{array}{l}\text { Freeze-thaw } \\
\text { splitting test }\end{array}$ & & Splitting strength ratio (\%) & $\begin{array}{l}0.87 \\
0.74\end{array}$ & 85.1 & $\begin{array}{l}0.93 \\
0.85\end{array}$ & 92.1 & $\begin{array}{l}0.96 \\
0.89\end{array}$ & 92.8 \\
\hline & Seepage test & - & Seepage coefficient $\left(\mathrm{mL} \cdot \mathrm{min}^{-1}\right)$ & Imper & eable & Impe & eable & Impe & leable \\
\hline
\end{tabular}

skeleton quality. The design of a DSAM based on this meso parameter can ensure that the coarse aggregates are interlocked to form the optimal main skeleton. It is a feasible method for designing DSAMs.

(2) By adjusting the gradation to increase the average coordination number and reduce the $C$ value, the meso parameter of the mixture can be effectively improved, and the quality of the main skeleton can be considerably improved. $\operatorname{VCA}_{\text {mix }}(\mathrm{IMAGE}) \leq$ $\mathrm{VCA}_{\mathrm{DRC}}$ and $\bar{n}_{\mathrm{c}}>1.6$ while $C<20 \%$ can be used as qualitative and quantitative evaluation criterion for forming better main skeleton structure of coarse aggregate. If allowed by the economic conditions, the use of an asphalt binder with higher performance to restrain the main skeleton can enhance its resistance to deformation and significantly improve the rutting resistance of the asphalt mixture.

(3) The new method of designing skeleton dense asphalt mixture based on meso parameter can realize precise design of asphalt mixture. The design process is intuitive and convenient, which considerably reduces the blindness and tediousness of the asphalt mixture gradation design. Because this method is a new aggregate gradation design method, it is necessary to further improve the design system on the basis of obtaining a large number of indoor and outdoor test data in the follow-up study.

\section{Data Availability}

The data of this study are available from the corresponding author upon request.

\section{Conflicts of Interest}

The authors declare that there are no conflicts of interest regarding the publication of this paper.

\section{Acknowledgments}

The authors would like to thank the National Natural Science Foundation of China (Grant nos. 51278203 and 51908130) for funding this research.

\section{References}

[1] I. M. Asi, "Laboratory comparison study for the use of stone matrix asphalt in hot weather climates," Construction and Building Materials, vol. 20, no. 10, pp. 982-989, 2006.

[2] Y.-f. Qiu, Y.-j. Liang, and Z.-h. Xu, "Study on improvement of judgment criterion for skeleton and dense texture," Journal of Highway and Transportation Research and Development, vol. 25, no. 8, pp. 10-14, 2008.

[3] Z.-s. Ge, X.-N. Zhang, and J.-M. Yu, "Mensuration for minimum void in coarse aggregate and its application," Journal of South China University of Technology (Natural Science Edition), vol. 37, no. 7, pp. 42-45, 2009.

[4] T. Ma, H. Wang, D. Zhang, and Y. Zhang, "Heterogeneity effect of mechanical property on creep behavior of asphalt mixture based on micromechanical modeling and virtual creep test," Mechanics of Materials, vol. 104, pp. 49-59, 2017.

[5] J. Li, P. Li, J. Su, Y. Xue, and W. Rao, "Effect of aggregate contact characteristics on densification properties of asphalt mixture," Construction and Building Materials, vol. 204, pp. 691-702, 2019.

[6] Y. Zhang, T. Ma, M. Ling, and D. Zhang, "Prediction of dynamic shear modulus of asphalt mastics by using the discretized element simulation and reinforcement mechanisms," Journal of Materials in Civil Engineering, vol. 31, no. 8, Article ID 04019163, 2019.

[7] N. Li, B. Ma, R. Li, and W. Si, "Performance of unbound aggregate materials under single-stage and multistage loading modes based on precision unbounded material analyzer," Journal of Highway and Transportation Research and Development (English Edition), vol. 13, no. 2, pp. 1-12, 2019.

[8] X. H. Ding, T. Ma, and X. Huang, "Discrete-element contourfilling modeling method for micro-and macro- mechanical analysis of aggregate skeleton of asphalt mixture," Journal of Transportation Engineering, Part B: Pavements.vol. 145, no. 1, Article ID 04018056, 2019. 
[9] I. S. Bessa, V. T. F. Castelo Branco, and J. B. Soares, "Evaluation of different digital image processing software for aggregates and hot mix asphalt characterizations," Construction and Building Materials, vol. 37, pp. 370-378, 2012.

[10] J. Jiang, Z. Zhang, Q. Dong, and F. Ni, "Characterization and identification of asphalt mixtures based on convolutional neural network methods using X-ray scanning images," Construction and Building Materials, vol. 174, pp. 72-80, 2018.

[11] M. E. Kutay, E. Arambula, N. Gibson, and J. Youtcheff, "Three-dimensional image processing methods to identify and characterise aggregates in compacted asphalt mixtures," International Journal of Pavement Engineering, vol. 11, no. 6, pp. 511-528, 2010.

[12] L. Shi, Z. Yang, D. Wang, X. Qin, X. Xiao, and M. K. Julius, "Gradual meso-Structural response behaviour of characteristics of asphalt mixture main skeleton subjected to load," Applied Sciences, vol. 9, no. 12, p. 2425, 2019.

[13] X. Wang, X. Gu, J. Jiang, and H. Deng, "Experimental analysis of skeleton strength of porous asphalt mixtures," Construction and Building Materials, vol. 171, pp. 13-21, 2018.

[14] M. R. Pouranian and J. E. Haddock, "Determination of voids in the mineral aggregate and aggregate skeleton characteristics of asphalt mixtures using a linear-mixture packing model," Construction and Building Materials, vol. 188, pp. 292-304, 2018.

[15] J. Chen, H. Wang, P. Xie, and H. Najm, “Analysis of thermal conductivity of porous concrete using laboratory measurements and microstructure models," Construction and Building Materials, vol. 218, pp. 90-98, 2019.

[16] M. Salemi and H. Wang, "Image-aided random aggregate packing for computational modeling of asphalt concrete microstructure," Construction and Building Materials, vol. 177, pp. 467-476, 2018.

[17] J. Jiang, F. Ni, L. Gao, and L. Yao, "Effect of the contact structure characteristics on rutting performance in asphalt mixtures using 2D imaging analysis," Construction and Building Materials, vol. 136, pp. 426-435, 2017.

[18] J. Jiang, F. Ni, L. Yao, and X. Cui, "Evaluating the mastic distribution of asphalt mixtures based on a new thickness threshold using 2D image planers," Road Materials and Pavement Design, vol. 11, no. 2, pp. 1422-1435, 2017.

[19] Y. Peng and L.-j. Sun, "Horizontal homogeneity in laboratorycompacted asphalt specimens," Road Materials and Pavement Design, vol. 15, no. 4, pp. 911-924, 2014.

[20] X. Ding, T. Ma, W. Zhang, D. Zhang, and T. Yin, "Effects by property homogeneity of aggregate skeleton on creep performance of asphalt concrete," Construction and Building Materials, vol. 171, pp. 205-213, 2018.

[21] C. Ling, A. Arshadi, and H. Bahia, "Importance of binder modification type and aggregate structure on rutting resistance of asphalt mixtures using image-based multi-scale modelling," Road Materials and Pavement Design, vol. 18, no. 4, pp. 785-799, 2017.

[22] N. R. Sefidmazgi, L. Tashman, and H. Bahia, "Internal structure characterization of asphalt mixtures for rutting performance using imaging analysis," Road Materials and Pavement Design, vol. 13, no. 1, pp. 21-37, 2012.

[23] H. Ying and H. Zhang, "Study distribution characteristics of aggregate contacts in AC20 HAM based on digital image processing," Journal of Building Materials, vol. 14, no. 1, pp. 66-70, 2011.

[24] L.-W. Shi, D.-Y. Wang, X. Cai, and Z.-Y. Wu, "Distribution characteristics of coarse aggregate contacts based on digital image processing technique," China Journal of Highway and Transport, vol. 27, no. 8, pp. 23-31, 2014.

[25] G. Lees, "The rational design of aggregate gradings for dense asphaltic compositions," in Proceedings of the Asphalt Paving Technologies, pp. 60-90, Kansas City, MO, USA, 1970.

[26] Y. A. Abdel-Jawad and W. S. Abdullah, "Design of maximum density aggregate grading," Construction and Building Materials, vol. 16, no. 8, pp. 495-508, 2002.

[27] X. Cai, Rutting Resistance Evaluation and Structure Optimization of Asphalt Pavement, South China University of Technology, Guangzhou, China, 2013.

[28] J. M. Yu, X. L. Zhan, L. Lu et al., "Optimal design for rut resistance of asphalt mixture," ournal of Highway and Transportation Research and Development, vol. 26, no. 9, pp. 1-5, 2009.

[29] L. Wang, X. Wang, L. Mohammad, and Y. Wang, "Application of mixture theory in the evaluation of mechanical properties of asphalt concrete," Journal of Materials in Civil Engineering, vol. 16, no. 2, pp. 167-174, 2004.

[30] W. Wu, D. Wang, X. Zhang, and X. Li, "Research on voids in coarse aggregate of asphalt mixtures with digital image processing and probability statistics," Journal of Tongji University (Nature Science).vol. 38, no. 12, pp. 1792-1795, 2010.

[31] L. Shi, D. Wang, W. Wu, and N. Qian, "Study of mixture skeleton based on digital image processing," Journal of Building Materials, vol. 4, no. 19, pp. 767-772, 2016.

[32] L. Rothenburg and N. P. Kruyt, "Critical state and evolution of coordination number in simulated granular materials," International Journal of Solids and Structures, vol. 41, no. 21, pp. 5763-5774, 2004.

[33] L. W. Shi and D. Y. Wang, "Evaluation indices of asphalt mixture main skeleton based on digital image processing," China Journal of Highway and Transport, vol. 30, no. 5, pp. 52-58, 2017.

[34] A. R. Coenen, M. E. Kutay, N. R. Sefidmazgi, and H. U. Bahia, "Aggregate structure characterisation of asphalt mixtures using two-dimensional image analysis," Road Materials and Pavement Design, vol. 13, no. 3, pp. 433-454, 2012.

[35] M. A. Elseifi, I. L. Al-Qadi, S. H. Yang, and S. H. Carpenter, "Validity of asphalt binder film thickness concept in hot-mix asphalt," Journal of the Transportation Research Board, vol. 2057, pp. 37-45, 2008.

[36] X. Cai, D.-Y. Wang, K. Li, and C. Wan, "Prediction of shear modulus of asphalt mixtures based on granular mechanics," China Journal of Highway and Transport, vol. 26, no. 6, pp. 38-46, 2013.

[37] China Communications Press, Highway Engineering Asphalt and Asphalt Mixture Test Procedures, China Communications Press, Beijing, China, 2011.

[38] China Communications Press, Technical Specification for Construction of Highway Asphalt Pavement, China Communications Press, Beijing, China, 2017. 